\title{
Statins and cardiovascular outcomes in elderly and younger patients with coronary artery disease: a post hoc analysis of the GREACE study
}

\author{
Vasilios G. Athyros' ${ }^{1}$ Niki Katsiki', Konstantinos Tziomalos², Thomas D. Gossios', Eleni Theocharidou', \\ Eygenia Gkaliagkousi ${ }^{1}$, Panagiotis Anagnostis ${ }^{4}$, Efstathios D. Pagourelias ${ }^{1}$, Asterios Karagiannis ${ }^{1}$, \\ Dimitri P. Mikhailidis ${ }^{5}$; for the GREACE Study Collaborative Group*
}

*20 co-investigators are listed in the acknowledgement section

1Second Propedeutic Department of Internal Medicine, Medical School,

Aristotle University of Thessaloniki, Hippokration Hospital, Thessaloniki, Greece

2First Propedeutic Department of Internal Medicine, Medical School,

Aristotle University of Thessaloniki, AHEPA University Hospital, Thessaloniki, Greece ${ }^{3}$ First Cardiology Clinic, Medical School, Aristotle University of Thessaloniki, AHEPA

University Hospital, Thessaloniki, Greece

${ }^{4}$ Endocrinology Clinic, Hippokration Hospital, Thessaloniki, Greece

${ }^{5}$ Department of Clinical Biochemistry (Vascular Prevention Clinic), Royal Free Campus, University College London Medical School, University College London (UCL), London, UK

Submitted: 30 March 2013

Accepted: 4 April 2013

Arch Med Sci 2013; 9, 3: 418-426

DOI: $10.5114 /$ aoms.2013.35424

Copyright @ 2013 Termedia \& Banach

\begin{abstract}
Introduction: The effect of cardiovascular disease (CVD) prevention measures aimed at elderly patients requires further evidence. We investigated the effect of statin treatment (targeted to achieve guideline goals) on CVD outcomes in different age groups to determine whether statins are more beneficial in the elderly.

Material and methods: The primary endpoint of this post hoc analysis of the GREek Atorvastatin and Coronary-heart-disease Evaluation (GREACE) study ( $n=1,600$ patients with established coronary heart disease (CHD), mean follow-up 3 years) was the absolute and relative CVD event (a composite of death, myocardial infarction, revascularization, unstable angina, heart failure and stroke) risk reduction in age quartiles (each $n=200)$. Patients on "structured care" with atorvastatin $(n=800)$ followed up by the university clinic and treated to lipid goal were compared with the corresponding quartiles on "usual care" $(n=800)$ followed up by specialists or general practitioners of the patient's choice outside the hospital.

Results: In the elderly (mean age $69 \pm 4$ and $70 \pm 3$ years in the "structured" and "usual care", respectively) the absolute CVD event reduction between "structured" and "usual care" was $16.5 \%(p<0.0001)$, while in the younger patients (mean age $51 \pm 3$ years and $52 \pm 3$ years in the "structured" and "usual care", respectively) this was $8.5 \%(p=0.016)$; relative risk reduction (RRR) $60 \%$ ( $p<$ $0.0001)$ vs. $42 \%$ respectively $(p=0.001)$. The elderly had higher rates of chronic kidney disease and higher uric acid levels, plus an increased prevalence of diabetes, metabolic syndrome and non-alcoholic fatty liver disease. These factors might contribute to the increased CVD risk in older patients.

Conclusions: All age groups benefited from statin treatment, but the elderly on "structured care" had a greater absolute and relative CVD risk reduction than the younger patients when compared with the corresponding patients assigned to "usual care". These findings suggest that we should not deprive older patients of CVD prevention treatment and lipid target achievement.
\end{abstract}

Key words: cardiovascular disease, age, statin, chronic kidney disease, GREek Atorvastatin and Coronary-heart-disease Evaluation.

\author{
Corresponding author: \\ Dimitri P. Mikhailidis MD, \\ FFPM, FRCP, FRCPath \\ Department of Clinical \\ Biochemistry \\ Royal Free Hospital Campus \\ University College \\ London Medical School \\ University College London \\ (UCL) \\ Pond Street \\ London NW3 2QG, UK \\ Phone: +44 2078302258 \\ Fax: +44 2078302235 , \\ E-mail: mikhailidis@aol.com
}




\section{Introduction}

Coronary heart disease (CHD) is the leading cause of death among the elderly and $>80 \%$ of all CHD deaths occur in patients $>65$ years old [1]. Life expectancy is steadily increasing but cardiovascular disease (CVD) risk substantially increases with age, creating a heavy burden of morbidity and mortality [1].

Studies such as the PROspective Study of Pravastatin in the Elderly at Risk (PROSPER) showed that the benefits of statin therapy extend to patients $>70$ years of age [2]. Nevertheless, there was no beneficial effect of pravastatin on stroke [2]. Other studies suggest that statin treatment benefits all age groups. Subgroup analyses from clinical trials (Scandinavian Simvastatin Survival Study (4S), Cholesterol and Recurrent Events (CARE), Long-term Intervention with Pravastatin in Ischaemic Disease (LIPID)) [3-5] demonstrated that simvastatin or pravastatin therapy significantly reduced the risk of CVD-related events in older patients (> 65 years old) to a similar level as for younger participants. Moreover, in the Treating to New Targets (TNT) [6] trial, older patients on atorvastatin $80 \mathrm{mg}$ had a relative risk reduction (RRR) in major CVD events that was similar to that for patients $<65$ years on atorvastatin $10 \mathrm{mg}$ [6].

Some survival studies showed that older people benefit more from statin treatment compared with younger people. In the Heart Protection Study (HPS) [7], the absolute RR in major CVD events among patients $\geq 65$ years of age on simvastatin $(40 \mathrm{mg} /$ day), compared with placebo, was higher than that in patients $<65$ years [6]. Moreover, the very old patients reported a better quality of life and more often achieved treatment targets than young stable angina patients [8]. Data also showed that in the elderly, the risk reduction (RR) is greater or equal to that in younger patients, but absolute RR was greater in the elderly because the event rate was higher [1].

In a large study on 20,132 male veterans, in all age groups, the magnitude of low-density lipoprotein cholesterol (LDL-C) reduction was proportional to the magnitude of CVD risk reduction [9], largely irrespective of the initial lipid profile or other presenting characteristics (including age). In a population study on 5,152 older people with diabetes mellitus (DM), statins reduced excess cardiovascular and all-cause mortality risk, irrespective of the presence or absence of CHD or glucose-lowering medication [10].

The magnitude and the mechanisms of CVD risk reduction in the elderly are not yet defined. This post hoc analysis of the GREek Atorvastatin and Coronary-heart-disease Evaluation (GREACE) study [11] was undertaken to investigate the effect of statin treatment (targeted to achieve guideline goals) on CVD outcomes in age groups divided by quartiles and not in a dichotomous way as for most studies [2-7].

\section{Material and methods}

\section{Study protocol}

The design and results (mortality, morbidity, cost-effectiveness and long-term safety) of the GREACE study, a "real-world study", have been described [11]. Briefly, this was a prospective, randomized, open label, intention-to-treat, and survival study. GREACE was conducted between 1998 and 2002 and was an unsponsored (investigator driven) study. Patients enrolled $(n=1,600)$ were men $(78 \%)$ and women (22\%) with CHD, aged $<75$ years old (mean age $58.3 \pm 13$ years). Baseline serum LDL-C levels were $>100 \mathrm{mg} / \mathrm{dl}(2.6 \mathrm{mmol} / \mathrm{l})$ and serum triglyceride (TG) levels $<400 \mathrm{mg} / \mathrm{dl}(4.5 \mathrm{mmol} / \mathrm{l})$.

All patients attended the outpatient atherosclerosis clinic of the Hippocration University Hospital, Thessaloniki, Greece, and if eligible were randomized either to "structured care" $(n=800)$, followed up by the university clinic, or to the "usual care" group $(n=800)$, followed up by specialists or general practitioners of the patient's trust and choice outside the hospital. In the "structured care" group, the starting dose of atorvastatin was $10 \mathrm{mg} /$ day. If the National Cholesterol Educational Program (NCEP) LDL-C goal (<100 mg/dl $(2.6 \mathrm{mmol} / \mathrm{l})$ ) [12] was not reached, the dose was titrated up to $80 \mathrm{mg} /$ day at 6-week intervals. Patients in the "usual care" group were treated according to their physicians' standard of care.

"Usual care" included life style changes, such as low-fat and hypocaloric (if needed) diet, weight loss, exercise plus all necessary drug treatment, including lipid-lowering agents. All patients were followed up for a mean 3-period with visits every 6 months.

In the present post hoc analysis participants in each "care" category were divided into quartiles $(n=200)$ and patients in each quartile of "structured care" were compared with the respective quartile of the "usual care" group. We did not use any cut-off age points. We included 200 patients in each quartile as their age was descending from the highest age to the lowest age.

\section{Laboratory investigations}

Serum lipids (total cholesterol (TC), LDL-C, highdensity lipoprotein cholesterol (HDL-C), and TGs), glucose, transaminase activities (alanine aminotransferase (ALT) and aspartate aminotransferase (AST)) and $\gamma$-glutamyl transpeptidase (GGT) were assessed at baseline, at the $6^{\text {th }}$ treatment week (dose titration visit) and every 6 months thereafter. Biochemical measurements were made on each serum sample using an Olympus AU 560 auto- 
analyser and appropriate reagents (Olympus $\mathrm{GmbH}$, Clare, Ireland). The reference range for ALT was 10$45 \mathrm{IU} / \mathrm{l}$, for AST 10-37 IU/I and for GGT 0-55 IU/I. All biochemical measurements were performed at the $6^{\text {th }}$ week (for statin dose titration purposes) and then every 6 months in all patients regardless of treatment or baseline levels of LTs. Serum creatinine $(\mathrm{SCr})$ was measured using the Jaffé method (reference range 0.6-1.3 mg/dl (55-115 $\mu \mathrm{mol} / \mathrm{l})$ ). Estimated glomerular filtration rate (eGFR) was calculated using the Modification of Diet in Renal Disease (MDRD) formula $\left(\mathrm{eGFR}=175 \times \mathrm{Scr}^{-1.154} \times\right.$ age $^{-0.203}(\times 0.742$ if female) $)$ [11]. Serum uric acid (SUA) concentrations were assessed using an enzymatic (uricase) colorimetric assay (reference range 150-415 $\mu \mathrm{mol} / \mathrm{l}(2.5-7.0 \mathrm{mg} / \mathrm{dl}))$. All the patients participating in the original study were included in the present post hoc analysis.

\section{Comorbidities}

All patients had an eGFR evaluation. Those with an eGFR value of $30-59 \mathrm{ml} / \mathrm{min} / 1.73 \mathrm{~m}^{2}$ (stage 3 chronic kidney disease (CKD)) were compared with those with an eGFR $>60 \mathrm{ml} / \mathrm{min} / 1.73 \mathrm{~m}^{2}$ (normal renal function or stage 1-2 CKD). Patients with an eGFR $<30 \mathrm{ml} / \mathrm{min} / 1.73 \mathrm{~m}^{2}$ were excluded from the study by the original study protocol.

In patients with abnormal liver tests (LTs), this was attributed to non-alcoholic fatty liver disease (NAFLD), after ultrasonographic diagnosis of this disease and after excluding other causes of elevated LTs (alcohol abuse (average use of pure alcohol $>20 \mathrm{~g} /$ day for men and $>10 \mathrm{~g} /$ day for women), chronic hepatitis B and C, Wilson's disease and autoimmune hepatitis). Thus, given that all patients had dyslipidaemia and that the vast majority of patients with abnormal LTs were obese, or had the metabolic syndrome (MetS) and/or diabetes mellitus (DM), abnormal LTs were mainly attributed to NAFLD. Liver-related adverse effects of statin treatment were defined as an elevation in ALT and/or AST activity $>3$-fold the upper limit of normal (ULN).

\section{Endpoints}

In this post hoc analysis of the GREACE study the primary endpoint was the decrease in CVD adverse events (all-cause and CVD mortality as well as CVD morbidity (non-fatal myocardial infarction, revascularization, unstable angina, congestive heart failure, and stroke)) in all age quartiles of patients $(n=200)$ on "structured care" compared with the corresponding age quartile of patients $(n=200)$ on "usual care". In respect to CVD events saved, the absolute and CVD relative risk reductions (RRR) were also calculated in all age quartiles and were compared with those of the other age quartiles. Secondary endpoints were the changes in eGFR,
SUA, and LTs in all age quartiles irrespective of the level of care. Other secondary endpoints were the differences between age groups in incidence of CKD, DM, MetS and smoking status.

\section{Statistical analysis}

All studied variables had a normal distribution as assessed by the Kolmogorov-Smirnov test. Variables are reported as mean and standard deviation (SD). The $\chi^{2}$ test was used for categorical variables, and Student $t$ test for continuous variables. Analysis of covariance (ANCOVA) was used to estimate significance among CVD event decrease in each age quartile, although the statistical power was substantially reduced by the separation of the study population in quartiles. The numbers need to treat (NNT) in each age quartile of structured care and their trend ( $p$ for trend) were calculated. At the end of the study ALT, AST, GGT, eGFR, and SUA values were calculated and were compared with baseline values. A 2-tailed $p<0.05$ was considered significant. All analyses were carried out using the SPSS 21.0 software (SPSS Inc., Chicago, IL).

\section{Results}

There were no significant differences in secondary CVD prevention treatments (aspirin, $\beta$-blockers, angiotensin-converting enzyme inhibitors) or patient parameters (arterial blood pressure or glycaemic control at baseline and on study) between the "structured" and "usual care" groups, except for statin treatment (at the start of the study in 1998 not all physicians in Greece prescribed statins for CHD patients). In the structured care group all patients were on atorvastatin; thus, in this group the NCEP LDL-C treatment goal was reached by $95 \%(n=759)$ of patients after dose titration of atorvastatin [11]. Only $14 \%$ of the "usual care" patients received any hypolipidaemic drugs throughout the study; $12 \%$ were on statins and only $3 \%$ of them reached the NCEP LDL-C treatment goal [11]. Thus, any difference recorded among the groups should be attributed to statin treatment.

Biological parameters in all age and different degrees of care categories are listed in Table I.

The mean age of patients in each age quartile was $51 \pm 3,57 \pm 4,63 \pm 3,69 \pm 4$ (ANCOVA $p=0.01$ ) for the "structured care" quartiles, and $52 \pm 3,58$ $\pm 3,64 \pm 4,70 \pm 3$ (ANCOVA $p=0.008$ ) for the "usual care" quartiles. The mean age difference in both levels of care between the lower and the upper age quartiles was $18 \mathrm{~s}$.

\section{Endpoints}

The primary endpoint was the difference in the CVD events reduction in the upper age quartile $(n=200)$ on "structured care" as compared with 
Table I. Parameters of study participants at baseline and at the end of the study in the upper age and lower age quartile, according to degree of care

\begin{tabular}{|c|c|c|c|c|c|c|}
\hline \multirow{3}{*}{$\begin{array}{l}\text { Parameter } \\
\text { Total cholesterol [mg/dl] }\end{array}$} & \multicolumn{3}{|c|}{$\begin{array}{l}\text { Lower age quartile of } \\
\text { structured care patients }(n=200)\end{array}$} & \multicolumn{3}{|c|}{$\begin{array}{c}\text { Upper age quartile of } \\
\text { structured care patients }(n=200)\end{array}$} \\
\hline & \multirow{2}{*}{$\begin{array}{l}\text { Baseline } \\
286 \pm 36\end{array}$} & \multicolumn{2}{|c|}{ End of study Percent change } & \multirow{2}{*}{$\frac{\text { Baseline }}{245 \pm 38}$} & \multicolumn{2}{|c|}{ End of study Percent change } \\
\hline & & $167 \pm 12$ & $-41^{\dagger \ddagger}$ & & $160 \pm 14^{\dagger \ddagger}$ & $-35^{\dagger \ddagger}$ \\
\hline LDL cholesterol [mg/dl] & $188 \pm 31$ & $102 \pm 4$ & $-46^{\dagger \ddagger}$ & $171 \pm 12$ & $96 \pm 8^{\dagger \ddagger}$ & $-44^{\ddagger \ddagger}$ \\
\hline HDL cholesterol [mg/dl] & $36 \pm 5$ & $38 \pm 4$ & 5 & $38 \pm 6$ & $41 \pm 5^{\dagger}$ & $5^{\dagger}$ \\
\hline Triglycerides [mg/dl] & $176 \pm 37$ & $125 \pm 42$ & $-29^{\dagger \ddagger}$ & $182 \pm 29$ & $124 \pm 15^{\dagger \ddagger}$ & $-32^{\dagger \ddagger}$ \\
\hline ALT [IU/I] & $32 \pm 9$ & $30 \pm 11^{\ddagger}$ & $-6^{\dagger \ddagger}$ & $42 \pm 14$ & $29 \pm 6^{\dagger \ddagger}$ & $-31^{\dagger \neq *}$ \\
\hline AST [IU/I] & $30 \pm 8$ & $27 \pm 9^{\ddagger}$ & $-10^{\dagger \ddagger}$ & $37 \pm 11$ & $26 \pm 6^{\dagger \neq}$ & $-30^{\dagger \neq *}$ \\
\hline GGT [IU/I] & $35 \pm 7$ & $30 \pm 8$ & $-14^{\dagger \ddagger}$ & $53 \pm 13$ & $30 \pm 5^{\dagger \ddagger}$ & $-44^{\dagger \neq *}$ \\
\hline eGFR $\left[\mathrm{ml} / \mathrm{min} / 1.73 \mathrm{~m}^{2}\right]$ & $72 \pm 12$ & $70 \pm 11$ & 2 & $63 \pm 10^{\dagger}$ & $73 \pm 8^{\dagger \ddagger}$ & $10^{\dagger \neq *}$ \\
\hline Serum uric acid [mg/dl] & $6.5 \pm 1$ & $6.4 \pm 2$ & -1 & $7.4 \pm 1$ & $6.6 \pm 1^{1 \ddagger}$ & $-11^{\dagger \neq *}$ \\
\hline \multirow[t]{2}{*}{ Parameter } & \multicolumn{3}{|c|}{$\begin{array}{c}\text { Lower age quartile of } \\
\text { usual care patients }(n=200)\end{array}$} & \multicolumn{3}{|c|}{$\begin{array}{c}\text { Upper age quartile of } \\
\text { usual care patients }(n=200)\end{array}$} \\
\hline & Baseline & \multicolumn{2}{|c|}{ End of study Percent change } & Baseline & \multicolumn{2}{|c|}{ End of study Percent change } \\
\hline Total cholesterol [mg/dl] & $268 \pm 35$ & $257 \pm 33$ & -4 & $242 \pm 38$ & $234 \pm 14$ & -3 \\
\hline LDL cholesterol [mg/dl] & $176 \pm 34$ & $170 \pm 29$ & -3 & $165 \pm 12$ & $161 \pm 11$ & -3 \\
\hline HDL cholesterol [mg/dl] & $38 \pm 5$ & $39 \pm 4$ & 3 & $38 \pm 6$ & $39 \pm 4^{\dagger}$ & 3 \\
\hline Triglycerides [mg/dl] & $173 \pm 37$ & $168 \pm 42$ & -4 & $179 \pm 28$ & $171 \pm 15$ & -4 \\
\hline ALT [IU/I] & $34 \pm 9$ & $38 \pm 11$ & 9 & $41 \pm 12$ & $45 \pm 13$ & 10 \\
\hline AST [IU/I] & $31 \pm 8$ & $32 \pm 9$ & 3 & $38 \pm 10$ & $42 \pm 12$ & 10 \\
\hline GGT [IU/I] & $28 \pm 7$ & $30 \pm 8$ & 7 & $51 \pm 15$ & $55 \pm 17$ & 8 \\
\hline eGFR [ml/min/1.73 m²] & $71 \pm 14$ & $70 \pm 10$ & 1 & $62 \pm 11$ & $58 \pm 13$ & -6 \\
\hline Serum uric acid [mg/dl] & $6.4 \pm 1$ & $6.8 \pm 1$ & 6 & $7.5 \pm 2$ & $7.9 \pm 2$ & 5 \\
\hline
\end{tabular}

${ }^{\dagger} p<0.05$ vs. baseline, ${ }^{\ddagger} p<0.05$ vs. respective quartile of "usual care", ${ }^{*} p<0.05$ vs. lower age quartile of "structured care". LDL - low-density lipoprotein cholesterol, HDL - high-density lipoprotein cholesterol, ALT - alanine aminotransferase, AST - aspartate aminotransferase, GGT- $\gamma$-glutamyl transpeptidase, e-GFR - estimated glomerular filtration rate

the respective quartile on "usual care" ( $n=200)$ vs. respective reductions in the lower age quartile $(n=200)$ on "structured care" as compared with the respective quartile on "usual care" $(n=200)$. The observed differences vs. "usual care" were 17 events $(8.5 \%$ reduction, $p=0.016)$ in the lowest age quartile, 22 events ( $11 \%$ reduction, $p=0.004$ ) in the second lowest age quartile, 28 events (14\% reduction, $p=0.0003$ ) in the third age quartile, and 33 CVD events (16.5\% reduction, $p<0.0001)$ in the highest age (elderly) quartile (Figure 1). However, significance using ANCOVA and $\chi^{2}$ test in pairs of quartiles did not reach statistical significance, probably as a result of the lack of statistical power due to the relatively small number of patients in each age quartile. The RRR were $42 \%, 48 \%, 53 \%$, and $60 \%$, as age increased in respective quartiles. The NNT with atorvastatin for 3 years were 11.7, 9.1, 7.2, 6.1 ( $p$ for trend $=0.001$ ), as age increased in respective quartiles, to avoid one CVD event. The NNT of the initial GREACE study (all patients on structured care) was 8 . The results on secondary endpoints, i.e. differences between age groups in the incidence of CKD, hyperuricaemia, DM, MetS, and smoking status (all CVD risk factors), are shown in Table II. The incidence of all the above were, as expected, higher in the elderly than in the younger patients. The values of biochemical parameters and the rate

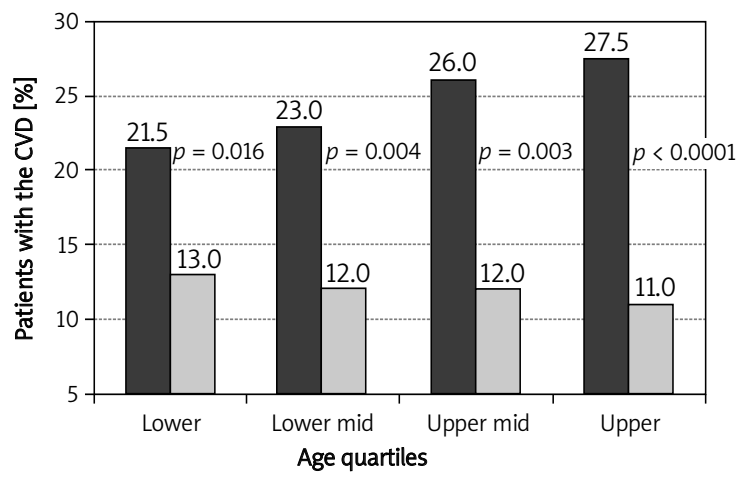

Figure 1. Percent of patients with any major cardiovascular (CVD) event (all-cause and CVD mortality as well as CVD morbidity (non-fatal myocardial infarction, revascularization, unstable angina, congestive heart failure, and stroke)) in all age quartiles in the "structured care" and the "usual care" groups 
Table II. Comorbidities in study participants at baseline and at the end of the study in the upper age and lower age quartile, according to degree of care

\begin{tabular}{|c|c|c|c|c|c|c|}
\hline \multirow{3}{*}{$\begin{array}{l}\text { Parameter } \\
\text { Men [\%] }\end{array}$} & \multicolumn{3}{|c|}{$\begin{array}{l}\text { Lower age quartile of } \\
\text { structured carepatients }(n=200)\end{array}$} & \multicolumn{3}{|c|}{$\begin{array}{l}\text { Upper age quartile of } \\
\text { structured care patients }(n=200)\end{array}$} \\
\hline & \multirow{2}{*}{$\begin{array}{c}\text { Baseline } \\
87\end{array}$} & \multicolumn{2}{|c|}{ End of study Percent change } & \multirow{2}{*}{$\begin{array}{c}\text { Baseline } \\
75\end{array}$} & \multicolumn{2}{|c|}{ End of study Percent change } \\
\hline & & - & - & & - & - \\
\hline Age [years] & $51 \pm 3$ & - & - & $69 \pm 4^{*}$ & - & - \\
\hline $\begin{array}{l}\text { Patients with } \mathrm{AH} \text { or on } \\
\text { antihypertensive drugs [\%] }\end{array}$ & $36^{*}$ & $35^{*}$ & $-3^{*}$ & $50^{*}$ & $52^{*}$ & $4^{*}$ \\
\hline $\begin{array}{l}\text { Patients with DM or on } \\
\text { hypoglycemic drugs [\%] }\end{array}$ & $12^{\star}$ & $13^{*}$ & $8^{*}$ & $25^{*}$ & $27^{*}$ & $8^{*}$ \\
\hline Patients with MetS [\%] & $28^{*}$ & $27^{*}$ & $-1^{*}$ & $41^{*}$ & $22^{\dagger *}$ & $-19^{\dagger \neq *}$ \\
\hline $\begin{array}{l}\text { Patients with stage } 3 \\
\text { CKD [\%] }\end{array}$ & $19^{*}$ & $18^{*}$ & $-1^{*}$ & $32^{*}$ & $21^{1 *}$ & $-11^{\dagger \neq *}$ \\
\hline Patients with NAFLD [\%] & $20^{*}$ & $9^{*}$ & $-11^{*}$ & $32^{*}$ & $9^{\dagger \star}$ & $-23^{\dagger \neq *}$ \\
\hline $\begin{array}{l}\text { Patients with } \\
\text { hyperuricaemia [\%] }\end{array}$ & $17^{\star}$ & $15^{\star}$ & $-2^{*}$ & $29^{*}$ & $17^{\dagger \star}$ & $-12^{\dagger \neq *}$ \\
\hline Current smokers [\%] & $18^{*}$ & $16^{*}$ & $-11^{*}$ & $8^{*}$ & $6^{*}$ & $-25^{\dagger \neq *}$ \\
\hline \multirow[t]{2}{*}{ Parameter } & \multicolumn{3}{|c|}{$\begin{array}{l}\text { Lower age quartile of } \\
\text { usual care patients }(n=200)\end{array}$} & \multicolumn{3}{|c|}{$\begin{array}{c}\text { Upper age quartile of } \\
\text { usual care patients }(n=200)\end{array}$} \\
\hline & Baseline & End of study & Percent change & Baseline & End of sti & cent change \\
\hline Men [\%] & 89 & - & - & 74 & - & - \\
\hline Age [years] & $52 \pm 3$ & - & - & $70 \pm 3^{*}$ & - & - \\
\hline $\begin{array}{l}\text { Patients with } \mathrm{AH} \text { or on } \\
\text { antihypertensive drugs [\%] }\end{array}$ & $35^{*}$ & $37^{\star}$ & $2^{*}$ & $52^{*}$ & $55^{\star}$ & $6^{*}$ \\
\hline $\begin{array}{l}\text { Patients with DM or on } \\
\text { hypoglycemic drugs [\%] }\end{array}$ & $11^{*}$ & $11^{*}$ & - & $22^{*}$ & $24^{*}$ & $9^{*}$ \\
\hline Patients with MetS [\%] & 29 & 32 & $10^{*}$ & $40^{*}$ & $44^{\star *}$ & $10^{*}$ \\
\hline $\begin{array}{l}\text { Patients with stage } 3 \\
\text { CKD [\%] }\end{array}$ & $21^{\star}$ & $23^{*}$ & $9^{*}$ & $30^{\star}$ & $35^{\star \star}$ & $16^{*}$ \\
\hline Patients with NAFLD [\%] & 20 & 21 & $5^{*}$ & $31^{*}$ & $35^{\star}$ & $13^{*}$ \\
\hline $\begin{array}{l}\text { Patients with } \\
\text { hyperuricaemia [\%] }\end{array}$ & $18^{*}$ & $20^{*}$ & $10^{* *}$ & $27^{*}$ & $30^{\star \star}$ & $11^{\star \star \star}$ \\
\hline Current smokers [\%] & $20^{*}$ & $18^{*}$ & $-2^{*}$ & $10^{*}$ & $9^{*}$ & $-1^{*}$ \\
\hline
\end{tabular}

${ }^{\dagger} p<0.05$ vs. baseline, ${ }^{\ddagger} p<0.05$ vs. respective quartile of "usual care", ${ }^{*} p<0.05$ vs. lower age quartile of "structured care". DM - diabetes mellitus, AH - arterial hypertension, NAFLD - non-alcoholic fatty liver disease, MetS - metabolic syndrome, CKD - chronic kidney disease

of comorbidities in the middle lower and the middle upper age quartile were in between those of the lowest and the upper age quartiles without significant differences with the upper and lowest quartiles of the respective level of care (data not shown).

\section{Discussion}

This post hoc analysis of the GREACE trial suggests that the clinical benefit increases with increasing patient age (Figure 1). It is of interest that the benefit of statin treatment in CHD patients during the 3-years follow-up was practically similar (the incidence of CVD events in structured care patients ranged from $11 \%$ to $13 \%$ for all age quartiles). However, the percentage and the absolute number of CVD events saved were increasingly higher with older age, because the "usual care" patients showed an increasing incidence of CVD events as age increased (from $21.5 \%$ in the lowest age quartile to $27.5 \%$ in the highest age quartile, $p=N S$ ) (Figure 1). Thus, the increased CVD risk of the older patients on "usual care" shaped the difference. This was also the case for the Intermountain Heart Collaborative Study, which included 7,220 individuals with angiographically defined significant CHD ( $\geq 70 \%$ stenosis) [13]. The mean follow-up was 3.3 years (similar to ours), and patients were divided into 3 age groups ( $<65,65-79$ and $\geq 80$ years) [13]. All age groups benefited, but although older patients were less likely to receive statin therapy, they had a greater absolute risk reduction. Relative risk reductions in mortality reached $50 \%$ for those 
$\geq 80$ years compared with $44 \%$ and $30 \%$ for individuals $65-79$ years old and those $<65$ years old, respectively, after adjusting for potential confounders [13].

Any clinical benefit in the upper age quartile in the present study could be related to the greater improvement of factors such as CKD, hyperuricaemia, and NAFLD in this age group than in the lower age quartile group. The risk of CVD in patients with CKD appears to be greater than in the general population, and a low GFR is an independent risk factor for CVD, de novo CVD, and all-cause mortality in the elderly based on population data [14, 15], registry data [16] and clinical studies $[17,18]$. An independent and graded association was detected between reduced eGFR and the risk of death, CVD events and all-cause hospitalizations [16]. Age-related decline in renal function in elderly subjects is associated with co-existing CVD and its risk factors [17]. Even mild CKD correlates with a higher CVD prevalence; the association of CKD with risk for adverse outcomes is strongly related to co-existing CVD and CVD risk factors [18]. It has been shown in survival studies that patients with CKD (up to stage 3) are indeed at a higher CVD risk but exhibit greater CVD risk reduction with effective treatment than those with normal kidney function $[19,20]$. A GREACE post hoc analysis showed that renal function declines over time and statin (mainly atorvastatin) treatment significantly improves renal function, thus offsetting an additional CVD risk factor [19]. The GFR increase was shown to be associated with CVD risk reduction, independent of the hypolipidaemic effect of the drug (backward stepwise regression analysis, adjusting for other CVD risk factors) [19]. The renal TNT post hoc analysis $(n=9,656)[20]$ confirmed that patients with stage 3 CKD $(n=3,107)$ have a higher risk for CVD events $(11.3 \%)$ vs. those with normal renal function (8.6\%) (hazard ratio $(\mathrm{HR})=1.35 ; 95 \%$ confidence interval $(\mathrm{Cl}) 1.18-1.54 ; p<0.0001)$. However, CKD patients on $80 \mathrm{mg} /$ day of atorvastatin had a $32 \%$ CVD event risk reduction $(\mathrm{HR}=0.68 ; 95 \% \mathrm{Cl} 0.55$ to $0.84 ; p=0.0003$ ) compared with CKD patients on $10 \mathrm{mg} /$ day of atorvastatin vs. a 15\% CVD event risk reduction in patients with normal eGFR on $80 \mathrm{mg} /$ day of atorvastatin $(\mathrm{HR}=0.85 ; 95 \% \mathrm{Cl} 0.72$ to $1.00 ; p=0.049$ ), compared with those on $10 \mathrm{mg} /$ day of atorvastatin [20]. eGFR was increased by up to $9.9 \%$ in those with CKD and $5.5-7.6 \%$ in those with normal renal function [21]. These findings suggest that in TNT, CVD risk reduction was greater in those patients with greater improvement of renal function, irrespective of LDL-C levels, supporting the earlier results of GREACE [19]. We also reported benefits in high-risk patients with MetS, DM, arterial hypertension and dyslipidaemia [22, 23]. Therefore, statins (mainly atorvastatin [24]) seem to offer protection in terms of vascular events across several stages of CKD and in CHD events ranging from acute myocardial infarction to stable CHD as well as in primary prevention [25]. These data might partly explain the greater reduction in CVD events in elderly patients, who had worse renal function than the younger ones, but also the greater improvement in eGFR, closely related to CVD event reduction [19-25]. Of note, clinicians should evaluate kidney function using certain formulae including MDRD, Cockcroft-Gault or the Chronic Kidney Disease Epidemiology Collaboration (CKD-EPI), as CKD patients may have normal serum creatinine levels, especially in the elderly population [26].

Whether SUA is a CHD risk factor [27] has remained controversial; for example, a correlation between SUA level and CVD events was not observed in the Framingham study [28]. Data from the National Health and Nutrition Examination Survey (NHANES) I epidemiological study $(n=5,926$, mean follow-up 16.4 years, 1,593 deaths) suggest that increased SUA levels are independently and significantly associated with risk of CVD mortality, after adjustment for several factors [29]. Similar were the conclusions of another study with a 14,262 personyears follow-up [30]. From the other side of the Pacific Ocean a prospective cohort study of 41,879 men and 48,514 women with a mean follow-up of 8.2 years recorded $1,151 / 5,427(21.2 \%)$ deaths that were attributed to CVD [31]. The results of this study reported that hyperuricaemia is an independent risk factor of mortality from all causes, CVD, and ischaemic stroke in the Taiwanese general population, in high-risk groups, and potentially in low-risk groups [31]. There is evidence linking SUA levels with CVD morbidity and mortality in high CVD risk patients [23, 32-38].

Atorvastatin treatment significantly reduces SUA levels in patients with CHD, thus offsetting another CHD risk factor [39]. After adjustment for $19 \mathrm{CHD}$ predictors, multivariate analysis involving backward stepwise logistic regression showed a HR of 0.89 (95\% Cl, 0.78 to $0.96 ; p=0.03$ ) with every $0.5 \mathrm{mg}$ $(30 \mu \mathrm{mol} / \mathrm{l})$ reduction in SUA levels, and an HR of $0.76(95 \% \mathrm{Cl}, 0.62$ to $0.89 ; p=0.001)$ with every $1 \mathrm{mg}$ $(60 \mu \mathrm{mol} / \mathrm{l})$ reduction in SUA levels. On the other hand, in patients untreated with a statin, SUA levels increased during the 3-duration of the GREACE study, recording an $\mathrm{HR}$ of $1.14(95 \% \mathrm{Cl}, 1.03$ to 1.27 ; $p=0.02)$ with every $0.5 \mathrm{mg}$ increase, and an HR of $1.29(95 \% \mathrm{Cl}, 1.17$ to $1.43 ; p=0.001)$ with every $1 \mathrm{mg}$ increase in SUA levels [39]. This association of SUA levels and estimated or actual CVD risk was also found in high-risk patients (with MetS, dyslipidaemia or hypertension) with or without CHD or DM $[22,23]$. These data might explain in part the greater reduction in CVD events in elderly patients, 
who had higher SUA levels at baseline compared with the younger participants, but also had the greater reduction during atorvastatin treatment.

The NAFLD is very common; one fifth to one third of adults worldwide have NAFLD [40-42]. Furthermore, NAFLD is even more frequent in the elderly (35.1\% in the Rotterdam Study) [43]. Patients with NAFLD have $69 \%$ higher all-cause mortality rates compared with the general population [44]. This higher risk was mainly due to CVD and to a lesser extent due to liver disease [44, 45]. Patients with non-alcoholic steatohepatitis (NASH; NAFLD + inflammation and fibrosis) had an even higher level of all-cause mortality [44]. Statin treatment may be safe in patients with NAFLD and can improve transaminase activity and the ultrasound features related to NAFLD [46]. Moreover, statin treatment reduces CVD morbidity in patients with mild to moderately abnormal transaminase activity due to NAFLD to a greater extent than in those without NAFLD $(68 \%$ vs. $39 \%$ relative risk reduction, $p=0.0074$ ) [46]. Similar benefit was recorded in other high-risk patients (with MetS, dyslipidaemia or hypertension) with or without CHD or DM [47-53]. These data might explain at least in part the greater reduction in CVD events in elderly patients, who had a higher incidence of NAFLD at baseline compared with the younger participants and a greater reduction in markers of NAFLD.

As expected, the elderly patients in the GREACE trial had a higher prevalence of DM than the younger ones. Of interest, there was not a significant number of new cases of DM with statin treatment [54-57] when statin therapy was part of a multifactorial approach. Furthermore, it is safe to prescribe statins in CHD patients with DM, even with CKD or NAFLD $[46,56,57]$. Finally, CHD patients with $\mathrm{DM}$ benefit more from statin treatment than those without DM $[58,59]$. Thus, better performance of the elderly might in part be attributed to the fact that there were more patients with DM in this age group.

Statin treatment decreases CVD events in both smokers and non-smokers [60] although this effect may be reduced in smokers [61]. There were fewer smokers in the elderly group than in the younger group and this may have played a role in the findings of the present study.

This study has several limitations. First, this is a post hoc analysis. Second, the number of patients included in each quartile was relatively small and did not allow multivariate analysis involving backward stepwise logistic regression in each group to show the exact level of significance. Also, only $22 \%$ of the study population were women and fewer were included in the lower age quartiles.

In conclusion, further studies are needed to clarify the precise level of benefit from anti-athero- sclerotic treatment in the elderly. Meanwhile, we should not deprive the elderly of lifestyle advice and optimal medical treatment and we should aim to achieve lipid guideline goals. Therefore, based on the results of the present analysis as well as other available clinical data $[62,63]$, statins should be used in the elderly, who are likely to benefit more than younger individuals.

\section{Acknowledgments}

We thank the following collaborators (20) for providing patient data: Baharoudis G, Basdekas S, Bouloukos V, Dimopoulou S, Giouleme O, Grammatiki M, Griva T, Kakafika A, Kargiotis K, Koumaras C, Lazaridis A, Mitsiou E, Papageorgiou A, Pehlivanidis A, Petridis D, Reklou A, Symeonidis A, Sekeri Z, Skaperdas A, Tzimou M.

\section{References}

1. Berthold HK, Gouni-Berthold I. Lipid-lowering drug therapy in elderly patients. Curr Pharm Des 2011; 17: 877-93.

2. Shepherd J, Blauw GJ, Murphy MB, et al.; PROSPER study group. PROspective Study of Pravastatin in the Elderly at Risk. Pravastatin in elderly individuals at risk of vascular disease (PROSPER): a randomised controlled trial. Lancet 2002; 360: 1623-30.

3. Miettinen TA, Pyorala K, Olsson AG, et al. Cholesterollowering therapy in women and elderly patients with myocardial infarction or angina pectoris: findings from the Scandinavian Simvastatin Survival Study (4S). Circulation 1997; 96: 4211-8.

4. Lewis SJ, Moye LA, Sacks FM, et al. Effect of pravastatin on cardiovascular events in older patients with myocardial infarction and cholesterol levels in the average range. Results of the Cholesterol and Recurrent Events (CARE) trial. Ann Intern Med 1998; 129: 681-9.

5. Prevention of cardiovascular events and death with pravastatin in patients with coronary heart disease and a broad range of initial cholesterol levels. The Long-Term Intervention with Pravastatin in Ischaemic Disease (LIPID) Study Group. N Engl J Med 1998; 339: 1349-57.

6. Wenger NK, Lewis SJ, Herrington DM, Bittner V, Welty FK; Treating to New Targets Study Steering Committee and Investigators. Outcomes of using high- or low-dose atorvastatin in patients $65 \mathrm{~s}$ of age or older with stable coronary heart disease. Ann Intern Med 2007; 147: 1-9.

7. Heart Protection Study Collaborative Group. MRC/BHF Heart Protection Study of cholesterol lowering with simvastatin in 20,536 high-risk individuals: a randomised placebo-controlled trial. Lancet 2002; 360: 7-22.

8. Rajendran S, Visvanathan R, Tavella R, Weekes AJ, Morgan C, Beltrame JF. In patients with chronic stable angina, secondary prevention appears better in the very old compared to younger patients: The Coronary Artery Disease in gENeral practiCE (CADENCE) Substudy. Heart Lung Circ 2012 Epub ahead of print.

9. Rahilly-Tierney CR, Lawler EV, Scranton RE, Gaziano JM. Cardiovascular benefit of magnitude of low-density lipoprotein cholesterol reduction: a comparison of subgroups by age. Circulation 2009; 120: 1491-7.

10. Olafsdottir E, Aspelund T, Sigurdsson G, et al. Effects of statin medication on mortality risk associated with type 
2 diabetes in older persons: the population-based AGESReykjavik Study. BMJ Open 2011; 1: e000132.

11. Athyros VG, Papageorgiou AA, Mercouris BR, et al. Treatment with atorvastatin to the National Cholesterol Educational Program goal versus 'usual' care in secondary coronary heart disease prevention. The GREek Atorvastatin and Coronary-heart-disease Evaluation (GREACE) study. Curr Med Res Opin 2002; 18: 220-8.

12. The Third Report of The National Cholesterol Education Program (NCEP) Expert Panel on Detection, Evaluation, And Treatment of High Blood Cholesterol In Adults (Adult Treatment Panel III). JAMA 2001; 285: 2486-97.

13. Allen Maycock CA, Muhlestein JB, Horne BD, et al.; Intermountain Heart Collaborative Study. Statin therapy is associated with reduced mortality across all age groups of individuals with significant coronary disease, including very elderly patients. J Am Coll Cardiol 2002; 40: 1777-85.

14. Culleton BF, Larson MG, Evans JC, et al. Prevalence and correlates of elevated serum creatinine levels: the Framingham Heart Study. Arch Intern Med 1999; 159: 1785-90.

15. Foley RN, Parfrey PS, Sarnak MJ. Epidemiology of cardiovascular disease in chronic renal disease. J Am Soc Nephrol 1998; 9 (12 Suppl): S16-23.

16. Go AS, Chertow GM, Fan D, McCulloch CE, Hsu CY. Chronic kidney disease and the risks of death, cardiovascular events, and hospitalization. N Engl J Med 2004; 351: 1296-305.

17. Baggio B, Budakovic A, Perissinotto E, et al.; ILSA Working Group. Atherosclerotic risk factors and renal function in the elderly: the role of hyperfibrinogenaemia and smoking. Results from the Italian Longitudinal Study on Ageing (ILSA). Nephrol Dial Transplant 2005; 20: 114-23.

18. Manjunath G, Tighiouart H, Coresh J, et al. Level of kidney function as a risk factor for cardiovascular outcomes in the elderly. Kidney Int 2003; 63: 1121-9.

19. Athyros VG, Mikhailidis DP, Papageorgiou AA, et al. The effect of statins versus untreated dyslipidaemia on renal function in patients with coronary heart disease. A subgroup analysis of the Greek atorvastatin and coronary heart disease evaluation (GREACE) study. I Clin Pathol 2004; 57: 728-34.

20. Shepherd J, Kastelein JJ, Bittner V, et al.; TNT (Treating to New Targets) Investigators. Intensive lipid lowering with atorvastatin in patients with coronary heart disease and chronic kidney disease: the TNT (Treating to New Targets) study. J Am Coll Cardiol 2008; 51: 1448-54.

21. Shepherd J, Kastelein JJ, Bittner V, et al.; Treating to New Targets Investigators. Effect of intensive lipid lowering with atorvastatin on renal function in patients with coronary heart disease: the Treating to New Targets (TNT) study. Clin J Am Soc Nephrol 2007; 2: 1131-9.

22. Athyros VG, Karagiannis A, Ganotakis ES, et al.; the Assessing the Treatment Effect in Metabolic Syndrome Without Perceptible Diabetes (ATTEMPT) Collaborative Group. Association between the changes in renal function and serum uric acid levels during multifactorial intervention and clinical outcome in patients with metabolic syndrome A post hoc analysis of the ATTEMPT study. Curr Med Res Opin 2011; 27: 1659-68.

23. Athyros VG, Hatzitolios Al, Karagiannis A, et al.; IMPERATIVE Collaborative Group. IMproving the imPlemEntation of cuRrent guidelines for the mAnagement of major coronary hearT disease rlsk factors by multifactorial interVEntion. The IMPERATIVE renal analysis. Arch Med Sci 2011; 7: 984-92.

24. Athyros VG, Karagiannis A, Kakafika A, Elisaf M, Mikhailidis DP. Statins and renal function. Is the compound and dose making a difference? Nephrol Dial Transplant 2007; 22: 963-4.

25. Athyros VG, Karagiannis A, Katsiki N, Mikhailidis DP. Statins in patients with renal dysfunction. Am J Cardiol 2012; 109: 1537.

26. Malyszko J, Bachorzewska-Gajewska H, Malyszko J, lainaLevin N, Kobus G, Dobrzycki S. Markers of kidney function in the elderly in relation to the new CKD-EPI formula for estimation of glomerular filtration rate. Arch Med Sci 2011; 7: 658-64.

27. Klein R, Klein BE, Cornoni JC, Maready J, Cassel JC, Tyroler HA. Serum uric acid: its relationship to coronary heart disease risk factors and cardiovascular disease, Evans County, Georgia. Arch Intern Med 1973; 132: 401-10.

28. Culleton BF, Larson MG, Kannel WB, Levy D. Serum uric acid and risk for cardiovascular disease and death: the Framingham heart study. Ann Intern Med 1999; 131: 7-13.

29. Fang J, Alderman MH. Serum uric acid and cardiovascular mortality the NHANES I epidemiologic follow-up study, 1971-1992. National Health and Nutrition Examination Survey. JAMA 2000; 283: 2404-10.

30. loachimescu AG, Brennan DM, Hoar BM, Hazen SL, Hoogwerf BJ. Serum uric acid is an independent predictor of all-cause mortality in patients at high risk of cardiovascular disease: a preventive cardiology information system (PreCIS) database cohort study. Arthritis Rheum 2008; 58: 623-30.

31. Chen JH, Chuang SY, Chen HJ, Yeh WT, Pan WH. Serum uric acid level as an independent risk factor for all-cause, cardiovascular, and ischemic stroke mortality: a Chinese cohort study. Arthritis Rheum 2009; 61: 225-32.

32. Katsiki N, Karagiannis A, Athyros VG, Mikhailidis DP. Hyperuricaemia: more than just a cause of gout? J Cardiovasc Med (Hagerstown) 2012 Epub ahead of print.

33. Katsiki N, Athyros VG, Karagiannis A, Mikhailidis DP. Hyperuricaemia and non-alcoholic fatty liver disease (NAFLD): a relationship with implications for vascular risk? Curr Vasc Pharmacol 2011; 9: 698-705.

34. Karagiannis A, Mikhailidis DP, Tziomalos K, et al. Serum uric acid as an independent predictor of early death after acute stroke. Circ J 2007; 71: 1120-7.

35. Daskalopoulou SS, Athyros VG, Elisaf M, Mikhailidis DP. Uric acid levels and vascular disease. Curr Med Res Opin 2004; 20: 951-4.

36. Bickel C, Rupprecht HJ, Blankenberg S, et al. Serum uric acid as an independent predictor of mortality in patients with angiographically proven coronary artery disease. Am J Cardiol 2002; 89: 12-7.

37. Eisen A, Benderly M, Goldbourt U, Haim M. Is serum uric acid level an independent predictor of heart failure among patients with coronary artery disease? Clin Cardiol 2013 Epub ahead of print.

38. Okura T, Higaki J, Kurata M, et al.; Japanese Coronary Artery Disease Study Investigators. Elevated serum uric acid is an independent predictor for cardiovascular events in patients with severe coronary artery stenosis: subanalysis of the Japanese Coronary Artery Disease (JCAD) Study. Circ J 2009; 73: 885-91.

39. Athyros VG, Elisaf M, Papageorgiou AA, et al.; GREACE Study Collaborative Group. Effect of statins versus untreated dyslipidemia on serum uric acid levels in patients with coronary heart disease: a subgroup analysis of the GREek Atorvastatin and Coronary-heart-disease Evaluation (GREACE) study. Am J Kidney Dis 2004; 43: 589-99.

40. Marchesini G, Bugianesi E, Forlani G, et al. Nonalcoholic fatty liver, steatohepatitis, and the metabolic syndrome. Hepatology 2003; 37: 917-23. 
41. Angulo P. Gl epidemiology: nonalcoholic fatty liver disease. Aliment Pharmacol Ther 2007; 25: 883-9.

42. Clark JM. The epidemiology of nonalcoholic fatty liver disease in adults. J Clin Gastroenterol 2006; 40 (Suppl 1): S5-10.

43. Koehler EM, Schouten JN, Hansen BE, et al. Prevalence and risk factors of non-alcoholic fatty liver disease in the elderly: results from the Rotterdam study. J Hepatol 2012; 57: 1305-11.

44. Söderberg C, Stål P, Askling J, et al. Decreased survival of subjects with elevated liver function tests during a 28 follow-up. Hepatology 2010; 51: 595-602.

45. Falck-Ytter Y, Younossi ZM, Marchesini G, McCullough AJ. Clinical features and natural history of nonalcoholic steatosis syndromes. Semin Liver Dis 2001; 21: 17-26.

46. Athyros VG, Tziomalos K, Gossios TD, et al.; GREACE Study Collaborative Group. Safety and efficacy of long-term statin treatment for cardiovascular events in patients with coronary heart disease and abnormal liver tests in the Greek Atorvastatin and Coronary Heart Disease Evaluation (GREACE) Study: a post-hoc analysis. Lancet 2010; 376: 1916-22.

47. Athyros VG, Giouleme O, Ganotakis ES, et al. Safety and impact on cardiovascular events of long-term multifactorial treatment in patients with metabolic syndrome and abnormal liver function tests: a post hoc analysis of the randomised ATTEMPT study. Arch Med Sci 2011; 7 796-805

48. Katsiki N, Athyros VG, Karagiannis A, Mikhailidis DP. Smoking and non-alcoholic steatohepatitis (NASH): the GREek Atorvastatin and Coronary heart disease Evaluation (GREACE) trial. J Hepatol 2012; 57: 476.

49. Athyros VG, Mikhailidis DP, Didangelos TP, et al. Effect of multifactorial treatment on non-alcoholic fatty liver disease in metabolic syndrome: a randomised study. Curr Med Res Opin 2006; 22: 873-83.

50. Liberopoulos EN, Athyros VG, Elisaf MS, Mikhailidis DP. Statins for non-alcoholic fatty liver disease: a new indication? Aliment Pharmacol Ther 2006; 24: 698-9.

51. Athyros VG, Tziomalos K, Daskalopoulos GN, Karagiannis A, Mikhailidis DP. Statin-based treatment for cardiovascular risk and non-alcoholic fatty liver disease. Killing two birds with one stone? Ann Med 2011; 43: 167-71.

52. Katsiki N, Athyros VG, Karagiannis A, Mikhailidis DP. Managing the combination of non-alcoholic fatty liver disease and metabolic syndrome. Expert Opin Pharmacother 2012; 13: 287-8

53. Tziomalos K, Athyros VG, Karagiannis A. Non-alcoholic fatty liver disease in type 2 diabetes: pathogenesis and treatment options. Curr Vasc Pharmacol 2012; 10: 162-72.

54. Athyros VG, Elisaf MS, Alexandrides T, et al. Assessing the Treatment Effect in Metabolic Syndrome Without Perceptible Diabetes (ATTEMPT) Collaborative Group. Long-term impact of multifactorial treatment on newonset diabetes and related cardiovascular events in metabolic syndrome: a post hoc ATTEMPT analysis. Angiology 2012; 63; 358-66.

55. Athyros VG, Mikhailidis DP. Pharmacotherapy: statins and new-onset diabetes mellitus: a matter for debate. Nat Rev Endocrinol 2012; 8: 133-4.

56. Athyros VG, Mikhailidis DP. Patient with hypertriglyceridemia, type 2 diabetes, and chronic kidney disease treated with atorvastatin and omega- 3 fatty acid ethyl esters. Open Cardiovasc Med J 2012; 6: 122-5.

57. Athyros VG, Tziomalos K, Karagiannis A, Mikhailidis DP. Dyslipidaemia of obesity, metabolic syndrome and type 2 diabetes mellitus: the case for residual risk re- duction after statin treatment. Open Cardiovasc Med J 2011 5: 24-34.

58. Athyros VG, Papageorgiou AA, Symeonidis AN, et al.; GREACE Study Collaborative Group. Early benefit from structured care with atorvastatin in patients with coronary heart disease and diabetes mellitus. Angiology 2003; 54: 679-90.

59. Shepherd J, Barter P, Carmena R, et al. Effect of lowering LDL cholesterol substantially below currently recommended levels in patients with coronary heart disease and diabetes: the Treating to New Targets (TNT) study. Diabetes Care 2006; 29: 1220-6.

60. Athyros VG, Tziomalos K, Katsiki N, et al.; the GREACE Study Collaborative Group. The impact of smoking on cardiovascular outcomes and comorbidities in statintreated patients with coronary artery disease: a post hoc analysis of the GREACE Study. Curr Vasc Pharmacol 2012 Epub ahead of print.

61. Milionis HJ, Rizos E, Mikhailidis DP. Smoking diminishes the beneficial effect of statins: observations from the landmark trials. Angiology 2001; 52: 575-87.

62. Szadkowska I, Stanczyk A, Aronow WS, et al. Statin therapy in the elderly: a review. Arch Gerontol Geriatr 2010; 50: 114-8.

63. Barylski M, Małyszko J, Rysz J, Myśliwiec M, Banach M. Lipids, blood pressure, kidney - what was new in 2011? Arch Med Sci 2011; 7: 1055-66. 